\title{
ADAPTABLE DUAL CONTROL SYSTEMS. A COMPARATIVE PARAMETRIC ANALYSIS
}

\author{
M.C. PHOCAS \& T.L. SOPHOCLEOUS \\ Department of Architecture, Faculty of Engineering, University of Cyprus, Nicosia, Cyprus.
}

\begin{abstract}
Structural control through energy dissipation systems has been increasingly implemented internationally in the last years and has proven to be a most promising strategy for earthquake safety of the structures. The control concept is based on the integration of passive damping devices within the structure for the necessary energy dissipation and the elastic response of the primary system. Adaptable dual control systems (ADCS) presented in this paper, consist of tension-only bracing members with closed circuit and a hysteretic damper of steel plates. The implementation of ADCS in frame structures enables a dual function of the component members, leading to two practically uncoupled systems, i.e. the primary frame, responsible for the static vertical and horizontal forces and the bracing-damper mechanism, for the earthquake forces and the necessary energy dissipation. ADCS are investigated and compared in their energy dissipation behavior for three differing configurations of the bracing-damper mechanism. In all cases the hysteretic damper utilizes effectively the relative displacements between its connection joints, i.e. a bracing and a primary frame's member, through its own yielding deformations for the necessary energy dissipation. In the present paper parametric dynamic analyses of the SDOF system's responses have been performed, based on three representative international earthquake motions of differing frequency contents. A nonlinear link parameter, defined as the ratio of the stiffness to the yield force of the hysteretic damper, DR, characterizes the behavior of the controlled systems in each configuration. Optimum DR values are proposed for each system configuration in achieving high energy dissipation capacity, while preventing possible increase of the maximum base shear and relative displacements.

Keywords: Adaptable Systems, Earthquake Resistance, Frame Structures, Passive Control.
\end{abstract}

\section{INTRODUCTION}

The design of frame structures with added control members for earthquake resistance refers primarily to the need for the primary systems to exhibit a linear elastic behavior under seismic actions. Passive metallic yielding, friction, viscoelastic and viscous damping devices may be added to frame structures to dissipate the input energy during an earthquake and to substantially reduce or eliminate damage to the primary frames [1,2]. In principle the damping devices are added in moment resisting frames, attached on steel bracings of large hollow section diagonals. Such bracing components increase the overall stiffness of the system, as they consist of steel members stressed in compression, tension and bending. Before yielding of the integrated damper's plates, the stiff bracings may reduce inter-story displacements, while producing high accelerations [3]. In addition the application of the members under compression leads under cyclic loading to a relatively inefficient behavior of the system, since in every half-loading cycle the compression diagonal buckles and it therefore cannot participate in the energy dissipation process.

Slender bracing members have found up to date limited applications for the integration of dampers in frame structures [4]. A reason for this is their tendency of becoming slack under tension yielding and compression buckling. In addition sudden increases of the tensile forces in the slender braces create detrimental impact loadings on the connections and the other structural members [5]. On the other hand the application of light-weight secondary systems 
for earthquake resistance seems to be a promising alternative as regards the avoidance of stiffness interaction with the primary system, as well as the achievement of both, simplicity and aesthetic qualities of the structures in the broader architectural context. The implementation of tension-only bracings with damping devices in frame structures may only be realized through the development of suitable bracing-damper configurations, whereas all bracing members would effectively contribute during the entire load duration to the operation of the integrated damper. In this way an optimization of the control system's operation principles for earthquake structural resistance may be achieved.

A control mechanism that enables the participation of all structural members in the energy dissipation process is the Pall-Marsh friction mechanism with slender cross braces, as configured in [6]. Under lateral loads, one pair of braces is subjected to tension and the other to compression. The rectangular damper deforms into a parallelogram, dissipating energy at the bolted joints through sliding friction. With the completion of a loading cycle, the resulting areas of the hysteresis loops are identical for both braces. An alternative of this friction mechanism with cross braces has been proposed in [7]. An implementation of chevron cable members with a friction damper consisting of three rotating plates and circular friction pad discs placed in between is described in [8].

In few other recently proposed light-weight control systems, hysteretic dampers are connected with slender bracing members that activate the former for the necessary energy dissipation through their joints' relative displacements. Hysteresis is achieved through optimization of the integrated hysteretic damper plates' section. Following these kinematical principles, the cross braces with the articulated quadrilateral with steel dissipaters work only in tension, whereas energy dissipation develops through elasto-plastic flexure of the steel plates with varying depth $[4,9]$. A similar cross cable bracing configuration has been proposed in [10], with a central energy dissipater consisting of two steel plates that are interconnected through a rotational spring and eight elastic cables. All cables are in tension under lateral loads. Under seismic excitation four cables in tension rotate the steel plates in opposite directions. The other four cables connecting across the shortened diagonal do not become slack, when the loading direction changes, due to the permanent rotation of the steel plates.

The research inquiry of utilizing the performance of mild steel in terms of strength, flexibility and minimal structural weight with the requirement for a smooth, non-coupled operation of the tension-only bracing-damper mechanism to the primary system under dynamic excitations has led to an initial proposal of a cross bracing mechanism of closed circuit with a hysteretic damper of steel plates [11]. During strong ground motions relative displacements between the bracing and the frame member interconnected through the hysteretic damper, induce deformations to the damper and energy dissipation. The bracing-damper mechanism is only responsible for the earthquake forces enabling in all cases the elastic response of the primary system. This kinematic system's principle has been applied in the development and improvement of further possible configurations for adaptable dual control systems, ADCS [12]. In principle, ADCS introduce a prototype connections design for the bracing members, based on rotating discs. The connection principle may be applied in different bracing configurations that share common features with respect to the kinetic model and the control behavior of the system [13]. Furthermore, the hysteretic damper applied in ADCS, may follow the section principles of hysteretic dampers subjected to shear forces at their connections. The dampers consist of X- or triangular-shaped steel plates for achieving uniform deformation curvatures over the sections' height, as applied in the examples of ADAS- and 
TADAS-devices [14-16]. The present analysis refers to three particular ADCS-configurations, a portal bracing, ADCS1, a portal- and a chevron bracing, ADCS2, and a bracing that forms with three cables a triangular shape, ADCS3. Each bracing's configuration provides obviously a differentiated seismic performance, but also an alternative structural form that can be applied within the broader architectural context of the building.

In the following sections ADCS configurations are introduced and the dynamic behavior of the controlled SDOF-models is analyzed. Based on three selected international strong ground motions with different frequency contents, the predominant parameters characterizing ADCS seismic behavior are derived with respect to the geometrical and mechanical properties of the members. Optimum ratio values of the elastic stiffness to the yield force, $\mathrm{DR}$, of the hysteretic damper are proposed for each system configuration to succeed in high energy dissipation capacity, while at the same time prevent possible increase of the maximum base shear and relative displacements.

\section{DESIGN CONFIGURATIONS}

ADCS are based on a dual function of the component members, resulting in two practically uncoupled systems. The primary frame is responsible for the static vertical and horizontal forces and the bracing-damper mechanism, for the earthquake forces and the necessary energy dissipation. ADCS enable the primary frame to respond elastically, while inelastic action is handled by the hysteretic damper acting as a second line of protection. In principle the control concept is based on achieving predefined performance levels through the property of deformation, rather than stiffness.

All bracing members of the proposed control systems are connected at the bottom of the columns and are free to move at their connecting joints to rotating mechanical discs, Fig. 1. In the configuration of the portal bracing, ADCS1, a hysteretic damper is placed between the beam and the horizontal bracing member. The same connection principle for the hysteretic damper applies in ADCS2. In the latter system, in addition to the portal bracing, a pair of chevron braces is connected to a middle eccentric disc connected at the lower horizontal connecting plate of the damper. In ADCS3 a hysteretic damper is placed between a secondary

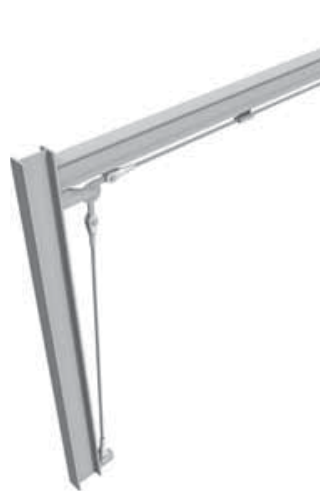

(a)

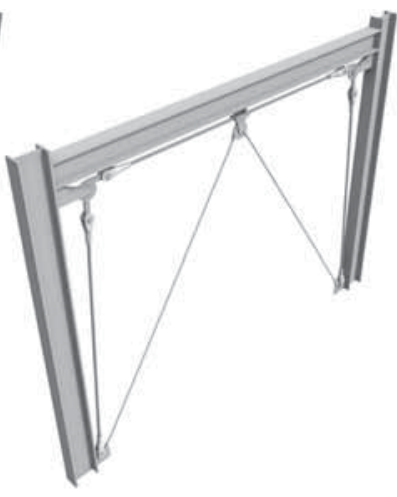

(b)

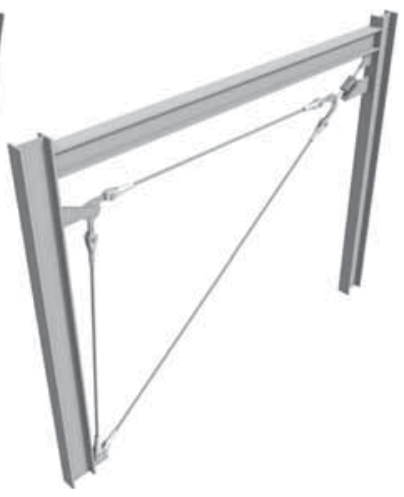

(c)

Figure 1: Adaptable dual control system with tension-only bracing-damper mechanism: (a) portal bracing configuration, ADCS1; (b) portal- and chevron bracing configuration, ADCS2; (c) triangular bracing configuration, ADCS3. 


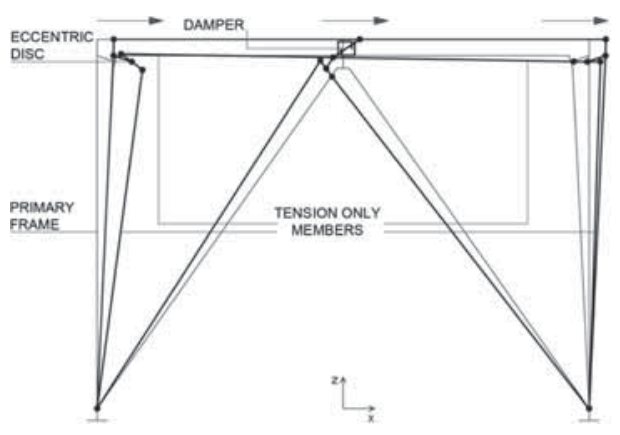

(a)

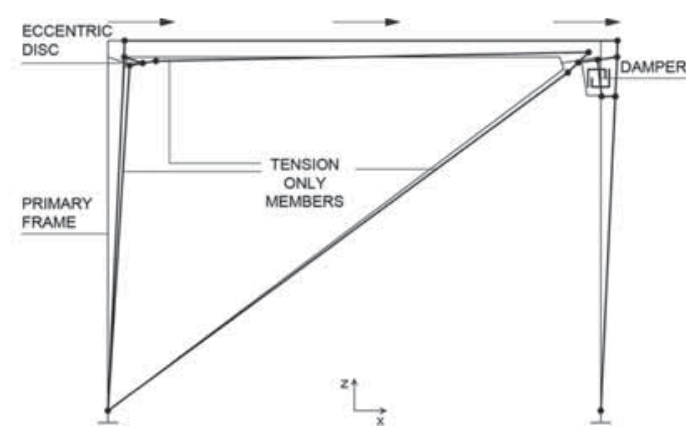

(b)

Figure 2: Kinetic systems' models: (a) ADCS2; (b) ADCS3.

cable and gusset plates welded to the column. The secondary cable in this case connects the frame's joint to a rotating U-shaped disc that connects the main bracing members. The optimum design of the hysteretic damper within each of the three system configurations enables maximum performance in utilizing the maximum relative displacement between the damper's connections. This is achieved through the respective shear forces acting on the damper's connections, as exemplified in [16]. The damper consists of a suitable number of identical triangular shaped, mild steel plates positioned in parallel and welded on two horizontal plates. The dampers plates' section lines reach their maximum yielding potential at the same time under the developed shear forces.

The kinetic mechanism of ADCS is activated during the dynamic excitation by the horizontally induced motion at the base of the structure. In every half-loading cycle the respective displacement of the primary frame is followed by the bracing members through rotations of the eccentric discs. The rotations of the connection joints at the discs result in respective axial displacements of the bracing, stretching the members. Since the bracing forms in all configurations kinetically closed circuits, ideally the reactions on the primary frame are neutralized and the bracing members remain under tension at the end of each excitation cycle, Fig. 2. The optimization of the bracing-damper mechanism involves tuning between the stiffness, the yield force and the deformations of the hysteretic damper due to shear, so that the energy flow in terms of hysteresis by the damper and the elastic strain energy in the tension-only bracings and the primary frame is effectively managed during the earthquake-induced motion. In addition the maximum base shear and the relative displacements of the controlled system should hold in bounds with the respective responses of the primary system.

\section{SYSTEM MODELS}

The finite element analysis of ADCS relies on a simplified model, whereas nonlinearity is only addressed with regard to the hysteretic damper, i.e. the nonlinear link. In real terms any large displacements would not need to be sustained by the primary frame, by itself, but by the composed system that contains the bracing-damper mechanism. The dynamic behavior of the SDOF model was examined with the SAP2000 software. A typical geometry was assigned for the ideal 2D-model of a moment resisting steel frame with a $6.0 \mathrm{~m}$ long beam and $4.5 \mathrm{~m}$ high column members. IPBv500 sections were assigned for the columns and IPBL550 for the beam $\left(\mathrm{S} 235, \mathrm{E}=2.1 \times 10^{4} \mathrm{kN} / \mathrm{cm}^{2}, \rho=78.5 \mathrm{kN} / \mathrm{m}^{3}\right)$. The dimensioning of the members was 
based on Eurocode 3, having assumed a static vertical load of $1200 \mathrm{kN}$, a horizontal wind load of $15 \mathrm{kN}$ and $25 \%$ of the vertical load as static equivalent seismic load. The primary frame's fundamental period results in $T=0.34 \mathrm{~s}$ and its stiffness $k=41717.37 \mathrm{kN} / \mathrm{m}$.

A diaphragm constraint at the roof level is required for the planar controlled systems that are intended to be part of a three-dimensional structure in real construction terms. Especially, the portal bracing in ADCS1 requires a rigid diaphragm in the perpendicular plane direction at the primary beam level, due to its high sensitivity in respect to out of plane deformations that influence negatively the respective energy flow during the seismic excitation. ADCS1 analytical results are obtained with the diaphragm constraint, assigned at the beam level. Typically the joints at the top of the columns are constrained as a diaphragm and the mass is equally concentrated at each of the two joints. The bracing members in this particular configuration consist of steel rods with constant diameter of $d_{c}=20 \mathrm{~mm}$. In ADCS2 and ADCS3, cables of the same diameter, i.e. $d_{c}=20 \mathrm{~mm}$, have been applied for all bracing members $\left(\mathrm{E}=1.6 \times 10^{4} \mathrm{kN} / \mathrm{cm}^{2}, f_{e}=140 \mathrm{kN} / \mathrm{cm}^{2}\right)$. The effective bracings' stiffness values $k_{b}$ for the three configurations amount to $27.78,2895.34$ and $4191.67 \mathrm{kN} / \mathrm{m}$ respectively. For the respective estimation the stiffness of the vertical bracing's member was decisive in ADCS1, whereas in ADCS2, the respective values of the vertical and diagonal braces connected in parallel, and in ADCS3, the stiffness of the diagonal bracing's member. The selection of a single bracing's diameter for the analysis follows initial investigations that concluded in the members' stiffness having insignificant influence on the energy dissipation performance of the integrated damper [17]. In all cases, the bracing members were modeled as frame objects with zero compression limits; in addition, as far as ADCS2 and ADCS3 are concerned, the cables were assigned a suitable pretension stress that would keep the members straight and taut when they are deformed. The rotating discs were modeled as a combination of three short frame members, each assigned with large stiffness values to represent the real property of a shaft.

\subsection{Mechanical properties of the hysteretic damper}

ADCS may result in significant energy dissipation, when all design parameters involved are predefined with respect to all selected seismic loading cases of the analysis. ADCS response for the desirable level of seismic protection depends primarily on the elastic lateral stiffness of the hysteretic damper, $k_{d}$, and the plastic yield force, $P_{y}$, of the device, given by the following equations:

$$
\begin{aligned}
& k_{d}=\frac{n E b t^{3}}{6 h^{3}} \\
& P_{y}=\frac{n f_{y} b t^{2}}{6 h}
\end{aligned}
$$

where $h$ is the steel plate's height, $b$ is the width, $t$ is the thickness, $n$ is the number of steel plates and $f_{y}$ is the yield stress $\left(\mathrm{S} 235, \mathrm{E}=2.1 \times 10^{4} \mathrm{kN} / \mathrm{cm}^{2}, f_{y}=24 \mathrm{kN} / \mathrm{cm}^{2}, \rho=78.5 \mathrm{kN} / \mathrm{m}^{3}\right)$.

Hysteretic dampers may exhibit an elasto-plastic or rigid-plastic behavior. The damper used in ADCS was modeled as a nonlinear link element. The damper's force-deformation relationship for the respective degree of freedom, corresponding to shear follows the hysteretic model described as Wen plasticity property type of uniaxial deformation [18]. The damper provides energy dissipation through its hysteretic behavior. Assuming that the kinetic 
Table 1: Hysteretic dampers' characteristics used for the numerical analysis.

\begin{tabular}{lcccccc}
$\begin{array}{l}\text { ADCS- } \\
\text { configuration }\end{array}$ & $\begin{array}{c}\text { Stiffness } k_{d} \\
{[\mathrm{kN} / \mathrm{m}]}\end{array}$ & $\begin{array}{c}\text { Yield force } P_{y} \\
{[\mathrm{kN}]}\end{array}$ & $\begin{array}{c}\text { Number of } \\
\text { plates } n\end{array}$ & $\begin{array}{c}\text { Thickness } \\
t[\mathrm{~cm}]\end{array}$ & $\begin{array}{c}\text { Height } \\
h[\mathrm{~cm}]\end{array}$ & $\begin{array}{c}\text { Width } \\
b[\mathrm{~cm}]\end{array}$ \\
\hline ADCS1 & $423.18-15748$ & $4.94-55.13$ & $1-11$ & $0.9-3.6$ & $5-40$ & $4-20$ \\
ADCS2 & $150-5250$ & $1.75-17.5$ & $2-6$ & $1.0-2.4$ & $20-40$ & 5 \\
ADCS3 & $112-24192$ & $2.60-42.66$ & $6-10$ & $0.8-2.0$ & $15-40$ & $4-6$ \\
\hline
\end{tabular}

energy of the system is dissipated within the first quarter of the hysteresis loop, the necessary yield force of the damper can be estimated by using the following expression:

$$
E_{H}=P_{y} D_{d} \Rightarrow P_{y}=\frac{E_{H}}{D_{d}}
$$

where $E_{H}$ is the dissipated plastic hysteretic energy, $P_{y}$ is the plastic yield force of the device and $D_{d}$ is the damper's deformation due to shear action. A design parameter, defined as damper ratio, DR, that describes ADCS response as a function of the damper's stiffness and yield force may be introduced, as follows:

$$
D R=\frac{k_{d}}{P_{y}}
$$

By substituting eqns (1) and (2) in eqn (4), DR may be written in the following form:

$$
D R=\frac{E t}{f_{y} h^{2}}
$$

For the investigation of the systems' seismic control effectiveness with respect to variations of the characteristic parameters of DR, a range of damper's stiffness and yield force values was combined in the numerical analyses, derived from a variable geometry of the steel plates, Table 1.

\subsection{Input seismic records}

The primary frame and the controlled systems were evaluated in their dynamic behavior under the action of three different selected strong earthquake excitations with differing energy content characteristics, Table 2 . The earthquake records represent moderately long, extremely irregular motions. The predominant periods of the ground motions range in their respective displacement response spectra between 1.5 and $3.0 \mathrm{~s}$. In the analysis no critical damping was considered for the model or the dynamic loading motions.

\section{SYSTEMS DYNAMIC RESPONSE}

\subsection{Natural period}

Earthquake resistant systems are characterized at first place by their fundamental period. Since the controlled system's period is only associated to the behavior of the system in its linear elastic range, it depends only on the two components' stiffness, i.e. the primary frame's 
Table 2: International seismic input records.

\begin{tabular}{lllccc}
\hline $\begin{array}{l}\text { Seismic } \\
\text { case }\end{array}$ & Record & Station & Mw & PGA [g] & Duration [s] \\
\hline A & El Centro 1940 & Imperial valley, component 180 & 6.9 & 0.348 & 53.76 \\
B & Kobe 1995 & JMA, component 0 & 6.9 & 0.810 & 48.00 \\
C & Northridge 1994 & Olive view, component 90 & 6.7 & 0.604 & 30.00 \\
\hline
\end{tabular}

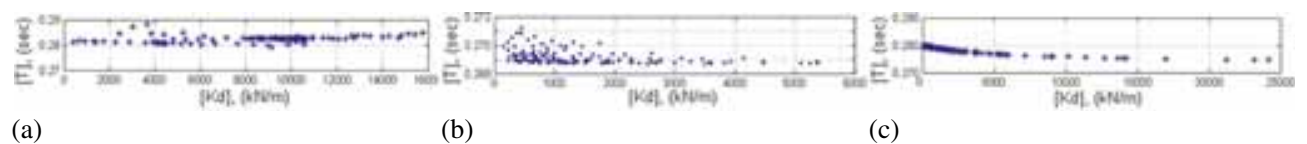

(a)

(b)

(c)

Figure 3: Controlled system's fundamental period $T$ to damper's stiffness $k_{d}$ : (a) ADCS1; (b) ADCS2; (c) ADCS3.

$k$ and the damper's stiffness $k_{d}$ that are linked in parallel, while remaining independent of $P_{y}$, which represents the nonlinear behavior of the damper [19]. Compared to the primary frame's fundamental period of $T=0.34 \mathrm{~s}$, ADCS1 period decreases slightly to the range of $0.278<T$ $<0.288$ s. ADCS2 and ADCS3 period decreases to the range of $0.268<T<0.272$ s and 0.275 $<T<0.28 \mathrm{~s}$ respectively. The similar results obtained for all three bracing-damper mechanisms provide first indications with respect to an insignificant stiffness-, base shear- and related input energy variations through their integration within the primary frame. The relation of the controlled systems' period with respect to the damper's elastic stiffness $k_{d}$ is shown in Fig. 3.

\subsection{Energy dissipation}

The controlled systems may be tuned to a specific predefined earthquake hazard protection level as defined by the designer in quantifiable energy measures of deformation. The system may be designed for a target performance level. In the present study the performance index for structural safety has been defined as effective energy deformation index, EEDI that physically represents the amount of input seismic energy dissipated by the hysteretic device in the entire seismic time duration. A number of 366, 397 and 342 combinations of assigned values of the damper's stiffness and yield force in terms of DR have been used in the parametric analysis of ADCS1, ADCS2 and ADCS3 respectively for all seismic cases. The ratio values of the hysteretic energy to the input energy of the systems are presented in Fig. 4, calculated for each value of DR. The energy ratio variation is marked on the $y$-axis, and the $x$-axis contains the design parameter DR.

The selected nonlinear parameter, DR, proposed to characterize the dynamic response behavior of the controlled systems, varies for ADCS1 between a minimum value of $\mathrm{DR}=64.291 / \mathrm{m}$ and a maximum value of $\mathrm{DR}=784.251 / \mathrm{m}$. Within this range of DR values the predominant characteristic design parameters of ADCS 1 are clearly distinguished. High energy dissipation by the controlled system, e.g. exceeding $70 \%$ of the input energy, may be achieved in the seismic loading cases $A$ and $C$ with values of DR $>3501 / \mathrm{m}$. For the same range of DR values, in seismic case B the control system dissipated in only 


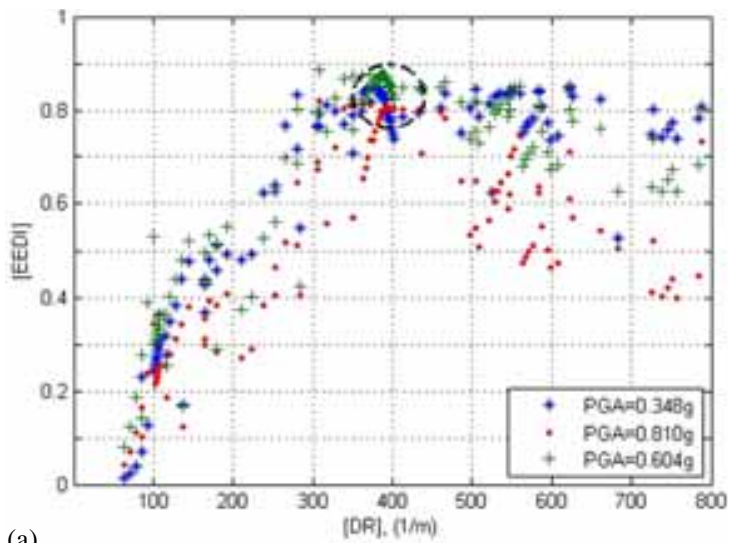

(a)
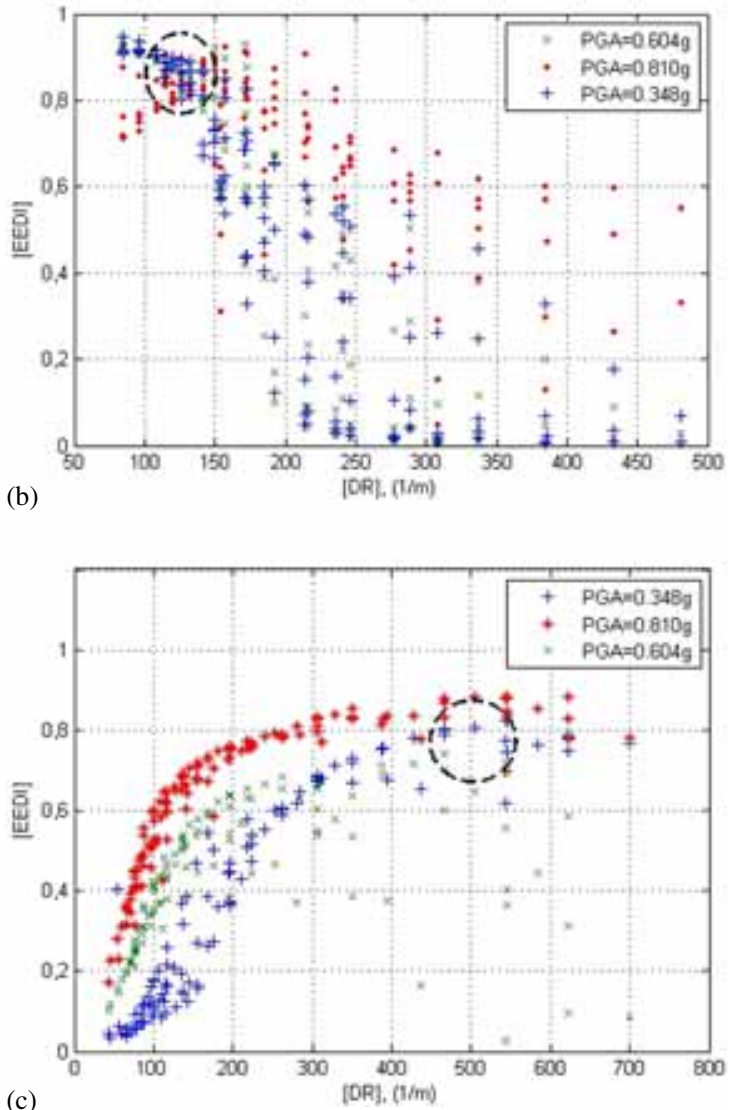

Figure 4: Effective energy deformation index EEDI to damper ratio DR for controlled systems: (a) ADCS1; (b) ADCS2; (c) ADCS3. 
some cases more than $60 \%$ of the input energy. Maximum energy dissipation for all three seismic cases is favored by values of $350<\mathrm{DR}<466.71 / \mathrm{m}$, taking into account the reduction of the controlled system's maximum base shear and -relative displacements also, as described in the following sections. ADCS1 energy dissipation is in particular less successful for low values of DR, i.e. DR $<3501 / \mathrm{m}$. In the entire DR range of analysis, the performance of ADCS1 was less satisfactory in the seismic case B with high peak ground acceleration.

In the case of ADCS2, DR varies in the analysis between a minimum value of DR = $84.221 / \mathrm{m}$ and a maximum value of $\mathrm{DR}=481.31 / \mathrm{m}$. In contrast to ADCS1, maximum energy dissipation for all three loading cases is achieved within a DR magnitude range of $100<\mathrm{DR}$ $<1501 / \mathrm{m}$. ADCS2 energy dissipation is in particular unsuccessful for high values of DR, i.e. DR $>4001 / \mathrm{m}$, especially for the low peak ground accelerations, PGA $<0.60 \mathrm{~g}$. ADCS2 performed comparatively better in the seismic case B with high peak ground acceleration, PGA $>0.80 \mathrm{~g}$. The high values of DR result from respective high values of $k_{d}$ that lead to an almost rigid-plastic behavior of the damper and cause certain time-delay in the initiation of the energy dissipation process.

In the last system's analysis case, DR varies between a minimum value of DR $=441 / \mathrm{m}$ and a maximum value of $\mathrm{DR}=7001 / \mathrm{m}$. High energy dissipation by ADCS3, e.g. exceeding $60 \%$ of the input energy, may be achieved in seismic case A with values of DR $>2841 / \mathrm{m}$. In seismic case $B$ the respective values of DR amount to DR $>1681 / \mathrm{m}$. In seismic case $C$ the control system may dissipate in only some cases more than $60 \%$ of the input energy, when DR $>2001 / \mathrm{m}$. Maximum energy dissipation for all three seismic cases are favored by DR values in the range of $437<\mathrm{DR}<5441 / \mathrm{m}$, taking into account also the reduction of the controlled system's maximum base shear and relative displacements. As in ADCS1, ADCS3 energy dissipation is in particular less successful for low values of DR, i.e. DR $<2401 / \mathrm{m}$, especially for low peak ground accelerations as in seismic case A described here. As ADCS2, ADCS3 performed comparatively better in general in the seismic case B with high peak ground acceleration.

The time variations of the systems' input- and dissipated energy leading to high energy dissipation performance by ADCS for all three seismic loading cases are shown in Fig. 5. The selected geometry of the damper's steel plates in ADCS1 amounts to $\mathrm{n}=2, \mathrm{t}=2.8 \mathrm{~cm}, \mathrm{~h}=$ $25 \mathrm{~cm}$ and $\mathrm{b}=10 \mathrm{~cm}$ (damper: 2282510), in ADCS2, $\mathrm{n}=6, \mathrm{t}=1.6 \mathrm{~cm}, \mathrm{~h}=35 \mathrm{~cm}$ and $\mathrm{b}=5 \mathrm{~cm}$ (damper: 616355) and in ADCS3, $\mathrm{n}=6, \mathrm{t}=1.2 \mathrm{~cm}, \mathrm{~h}=15 \mathrm{~cm}$ and $\mathrm{b}=5 \mathrm{~cm}$ (damper: 612155). The respective optimum DR values of the control systems enable maximum energy dissipation in all three seismic cases, but also hold the controlled systems' responses, i.e. maximum base shear and relative displacements, in bounds with the respective responses of the primary system. The optimum DR values that govern the design of ADCS and the resulting EEDI values are presented in Table 3.

In the parametric study the dampers plates' height, $h$, proved to influence stronger the systems' behavior than the other geometric parameters, according also to eqn (5). The form of the corresponding hysteresis curves depends primarily on the level of the plastic hysteretic damping. In ADCS1 the selected hysteretic damper develops in seismic case A primarily hysteresis curves of the elasto-plastic type model, in cases B and C, of the rigid-plastic type model. In the other ADCS-configurations the selected hysteretic dampers develop in all three seismic cases hysteresis curves of the rigid-plastic type model. Especially in the latter cases the dampers determine the dynamic behavior of the systems. 

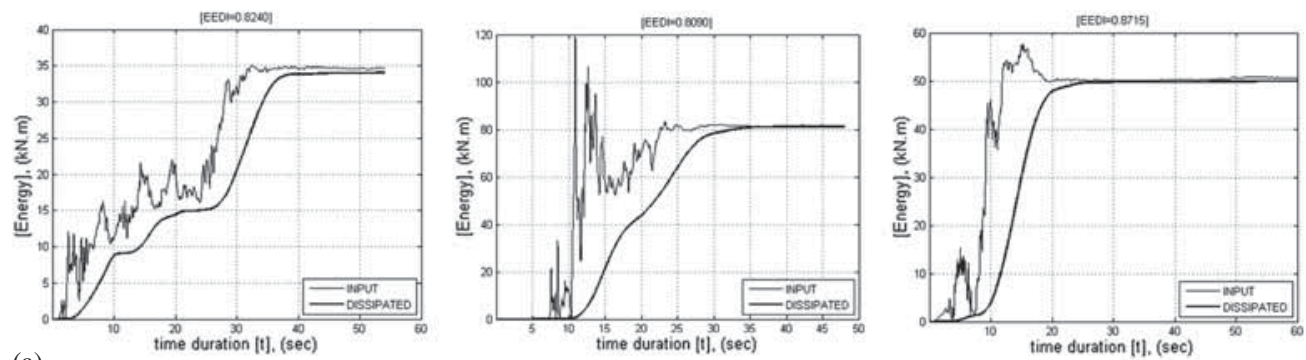

(a)
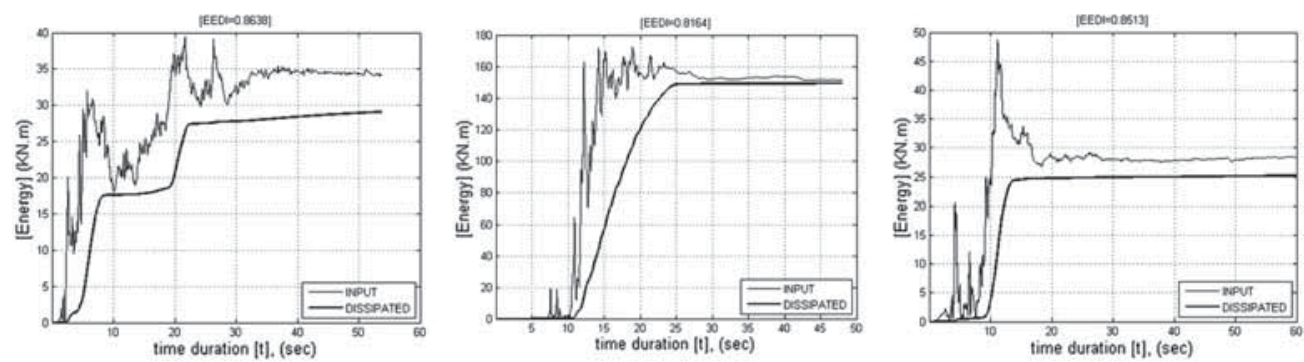

(b)
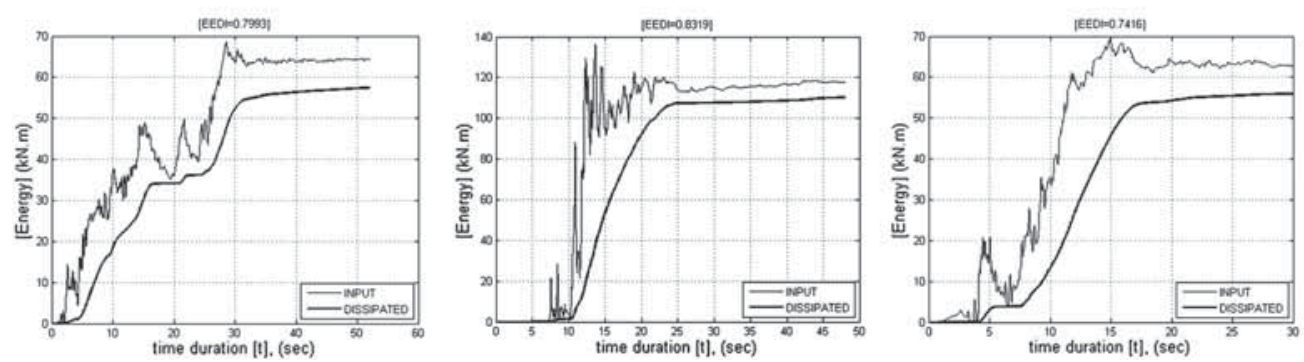

(c)

Figure 5: Hysteretic damper's energy dissipation- and force-deformation behavior for seismic case A, B, C (from left to right): (a) ADCS1-damper 2282510; (b) ADCS2-damper 616355; (c) ADCS3-damper 612155.

Table 3: ADCS optimum energy dissipation performance (ADCS1-damper 2282510, ADCS2-damper 616355, ADCS3-damper 612155).

Energy dissipation ratio EEDI [\%]

\begin{tabular}{lllcccc} 
& & & & \multicolumn{3}{c}{ Seismic case } \\
\cline { 5 - 7 } $\begin{array}{l}\text { ADCS- } \\
\text { configuration }\end{array}$ & DR $[1 / \mathrm{m}]$ & $k_{d}[\mathrm{kN} / \mathrm{m}]$ & $P_{y}[\mathrm{kN}]$ & $\mathrm{A}$ & $\mathrm{B}$ & $\mathrm{C}$ \\
\hline ADCS1 & 392 & 9835 & 25.09 & 82.40 & 80.90 & 87.15 \\
ADCS2 & 114.3 & 1003.10 & 8.78 & 86.38 & 81.64 & 85.13 \\
ADCS3 & 466.67 & 5376 & 11.52 & 79.93 & 83.19 & 74.16 \\
\hline
\end{tabular}




\subsection{Base shear}

Observations on the energy behavior of structures, into which hysteretic dampers are incorporated, concluded that the energy input tends to increase as to the system's stiffness after the damper's yielding, while becoming less insensitive to the systems yield strength [19]. A possible increase in the energy input back to the seismic control system may lead to damage under repeated excitation cycles. ADCS maximum base shear responses did not increase significantly in any analysis case. The magnitudes of base shear are presented in absolute values in Fig. 6 as a function of DR.

Within the selected DR values for optimum energy dissipation performance of ADCS, i.e. $350<$ DR $<466.7,100<$ DR $<150$ and $437<$ DR $<5441 /$ m for the three systems respectively, the base shear of the controlled systems obtained the lowest values. The time-history of the primary frame's base shear (light line) to the controlled systems' base shear responses (bright line) under the three seismic loading cases, for the optimum DR values of ADCS is shown in Fig. 7. Compared to the primary frame's base shear, ADCS1 maximum response decreases for a DR value of $3921 / \mathrm{m}$ (damper: 2282510) by $35 \%$ in seismic case A and $26 \%$ in case $\mathrm{B}$, whereas in case $\mathrm{C}$ it increases by almost $5 \%$. ADCS2 respective responses for a DR value of $114.31 / \mathrm{m}$ (damper: 616355) amount to a decrease of $8 \%$ in seismic case A, 13 $\%$ in case B, and an increase of almost $2 \%$ in case C. Finally ADCS3 respective responses decrease for a DR value of $466.61 / \mathrm{m}$ (damper: 612155 ) by $16 \%$ in seismic case A, and almost by $28 \%$ in case B, whereas in case $\mathrm{C}$ an increase of $1 \%$ can be observed, Table 4 . The average decreases of the maximum base shear due to ADCS amount to 18.7, 6.3 and $14.3 \%$ respectively.

\subsection{Relative displacements}

The systems' relative displacements variations have been investigated for indication of some major trend characteristics in their response behavior. The magnitudes of the systems' relative
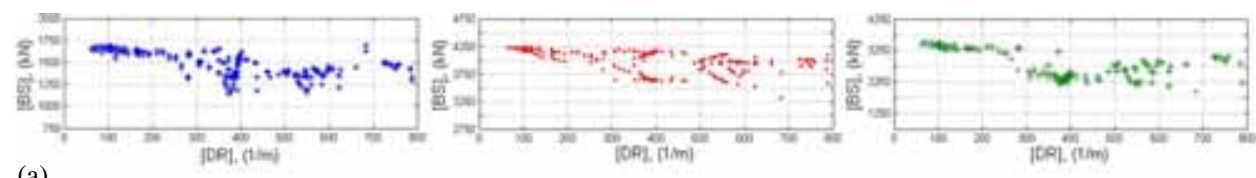

(a)
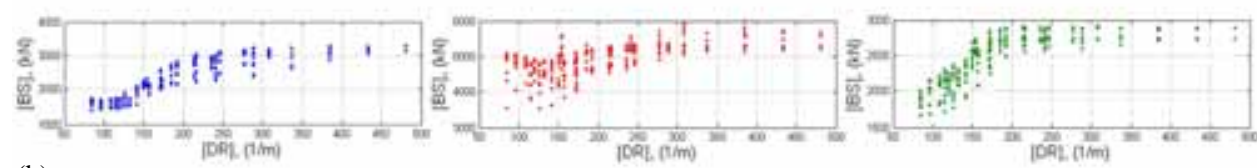

(b)
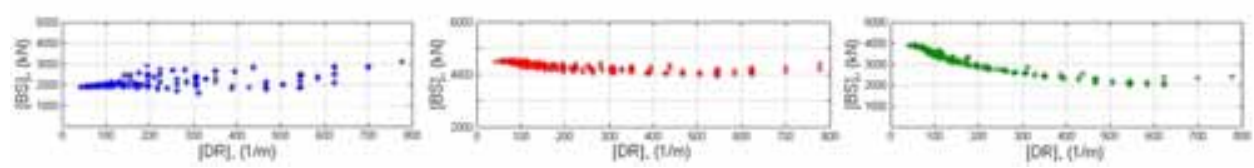

(c)

Figure 6: Controlled systems' maximum base shear BS to damper ratio DR for seismic case A, B, C (from left to right): (a) ADCS1; (b) ADCS2; (c) ADCS3. 


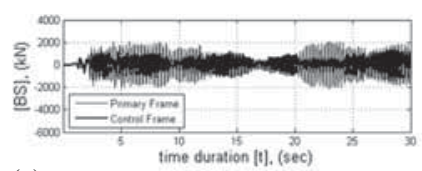

(a)
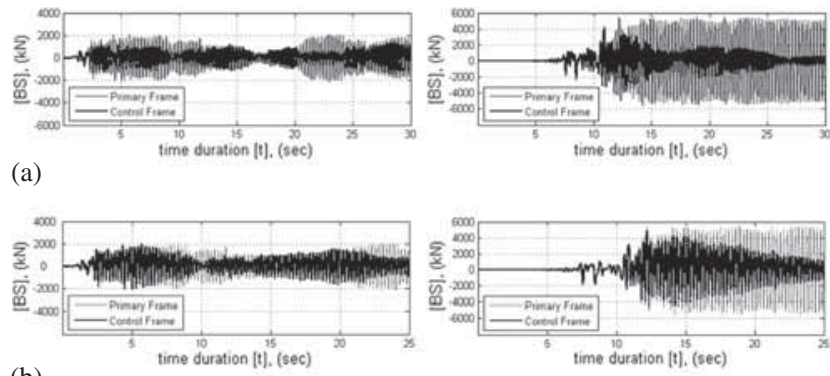

(b)
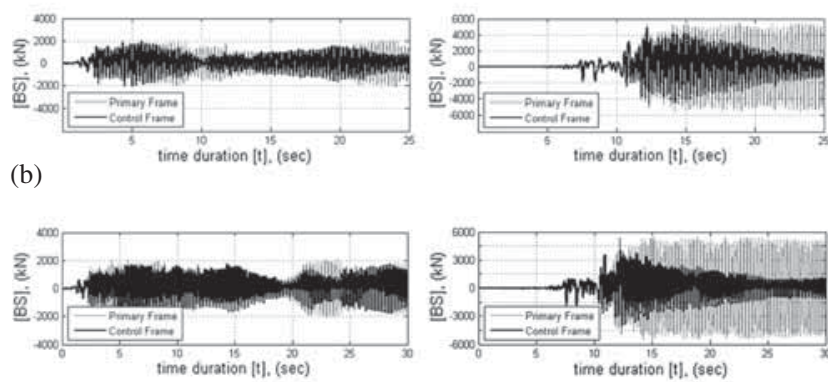

(c)

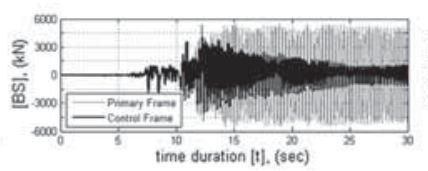

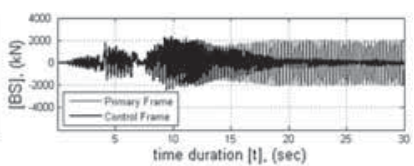
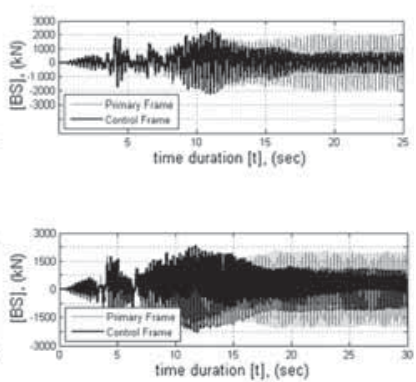

Figure 7: Primary and optimum controlled systems' base shear BS - time history for seismic case A, B, C (from left to right): (a) ADCS1; (b) ADCS2; (c) ADCS3.

Table 4: Primary frame's and optimum ADCS base shear response.

\begin{tabular}{lccc}
\hline & \multicolumn{3}{c}{ Max. base shear $[\mathrm{kN}]$} \\
\cline { 2 - 4 } System & \multicolumn{3}{c}{ Seismic case } \\
\cline { 2 - 4 } Primary frame & 2102 & 5570 & C \\
ADCS1 & 1374 & 4139 & 2304 \\
ADCS2 & 1932 & 4830 & 2340 \\
ADCS3 & 1764 & 4031 & 2321 \\
\hline
\end{tabular}

displacements are presented in absolute values in Fig. 8 as a function of DR. In ADCS1 the minimum response values occur within the range of $350<\mathrm{DR}<466.71 / \mathrm{m}$, in ADCS2, within the range of $100<\mathrm{DR}<1501 / \mathrm{m}$ and in ADCS3, within the range of $437<\mathrm{DR}<544$ $1 / \mathrm{m}$. With respect to optimum DR ranges, the systems' relative displacement responses are in agreement with the respective base shear responses. In ADCS1 the controlled system's maximum relative displacement decreased significantly for the entire DR range of values, compared to the respective primary frame's response, especially in the seismic case A and B with lowest and highest peak ground acceleration respectively. In case $\mathrm{C}$ an increase of the controlled system's maximum relative displacement was observed with a respective decrease of DR, reaching an upper value of $5.503 \mathrm{~cm}$. The most unfavorable responses for seismic case $\mathrm{A}$ and $\mathrm{B}$ amount to 2.332 and $5.794 \mathrm{~cm}$ respectively. ADCS2 exhibited a different behavior, since the relative displacements of the system are kept low only with relatively low values of $k_{d}$ and DR. For high DR values the maximum relative displacements have an upper value of $4.0 \mathrm{~cm}$ in seismic case $\mathrm{C}$, and $7.0 \mathrm{~cm}$ in seismic case B. ADCS3 respective responses are similar to ADCS1, whereas in seismic case $\mathrm{C}$ a considerable increase of the maximum relative 


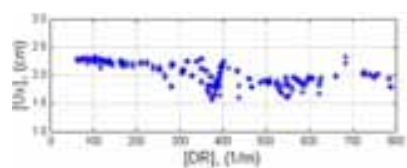

(a)

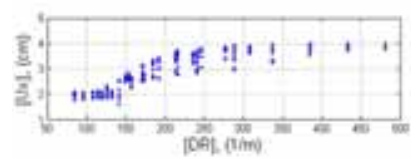

(b)

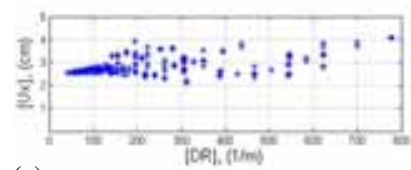

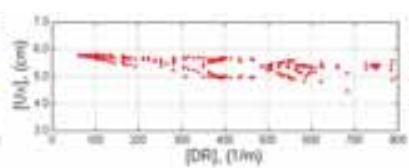
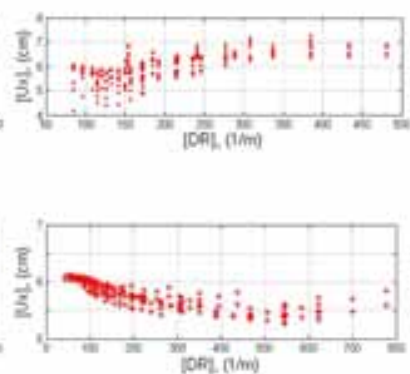
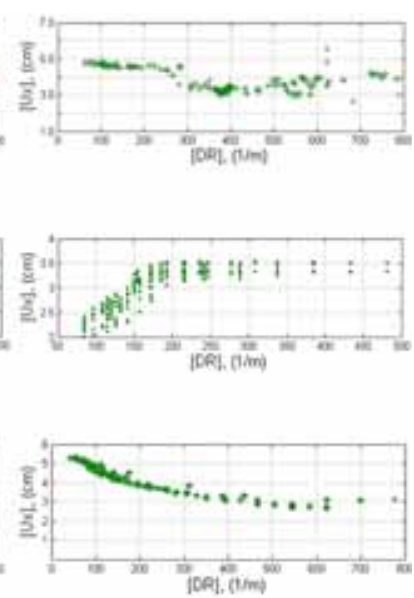

(c)

Figure 8: Controlled systems' maximum relative displacements $\mathrm{U}_{\mathrm{x}}$ to damper ratio DR for seismic case A, B, C (from left to right): (a) ADCS1; (b) ADCS2; (c) ADCS3.

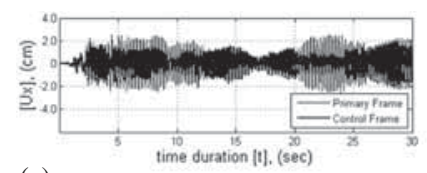

(a)

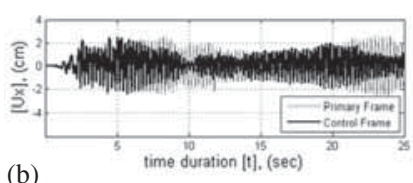

(b)

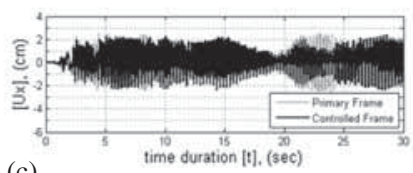

(c)
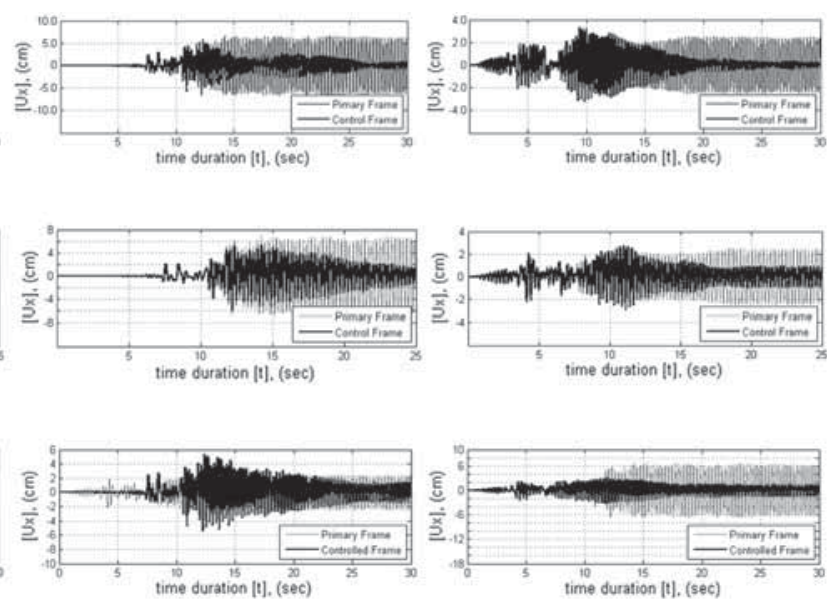

Figure 9: Primary and optimum controlled systems' relative displacements $U_{x}-$ time history for seismic case A, B, C (from left to right): (a) ADCS1; (b) ADCS2; (c) ADCS3.

displacement was observed with a respective decrease of DR reaching an upper value of $5.348 \mathrm{~cm}$. The respective most unfavorable responses for seismic case A and B amount to 4.10 and $6.131 \mathrm{~cm}$, respectively.

The time-history of the primary frame's relative displacements (light line) to the controlled systems' relative displacements (bright line) under the three seismic loading cases, for the optimum DR values of ADCS is shown in Fig. 9. The reduction of the controlled system's maximum relative displacements compared to the respective values of the primary frame in ADCS1 for a DR value of $3921 / \mathrm{m}$ (damper: 2282510) amounts to approximately $26 \%$ in seismic case A and $17 \%$ in case B. In the seismic case C the controlled system's maximum relative displacement increased by $19 \%$ compared to the maximum value of the primary 
Table 5: Primary frame's and optimum ADCS relative displacements response.

\begin{tabular}{lccc}
\hline & \multicolumn{3}{c}{ Max. relative displacement [cm] } \\
\cline { 2 - 4 } System & \multicolumn{3}{c}{ Seismic case } \\
\cline { 2 - 4 } Primary frame & A & B & C \\
ADCS1 & 2.561 & 6.779 & 2.805 \\
ADCS2 & 1.906 & 5.628 & 3.330 \\
ADCS3 & 2.336 & 5.759 & 2.828 \\
\hline
\end{tabular}

frame. ADCS2 respective responses for a DR value of 114.31/m (damper: 616355) amount to a decrease of almost $9 \%$ in seismic case A and $15 \%$ in case B, and an increase of almost $1 \%$ in case $\mathrm{C}$. ADCS3 respective responses decrease for a DR value of $466.671 / \mathrm{m}$ (damper: 612155) by $7 \%$ in seismic case A, $20 \%$ in case B, whereas in case $\mathrm{C}$ an increase by almost $12 \%$ is observed, Table 5 . The relative displacements of the controlled systems reduce thus on average by $8 \%$ in ADCS 1 and ADCS 2 and by $5 \%$ in ADCS3.

\subsection{Damper's shear deformations}

In ADCS1 and ADCS2 the hysteretic damper is positioned at the horizontal midpoint between the horizontal bracing member and the beam, so that its shear deformations reach maximum values through relative displacements of the primary system to the bracing member attached. In addition, in ADCS2, the chevron bracing connected to the eccentric disc of the lower horizontal connecting plate of the damper induces further increase of the damper's shear deformations during the frame motion through its re-centering action. In ADCS3, shear deformations of the hysteretic damper are activated through relative displacements of the primary column to the secondary member of the bracing mechanism. The time-history of the damper's shear deformations under the three seismic loading cases for the optimum DR values of ADCS is shown in Fig. 10. In ADCS1, for a DR value of $3921 / \mathrm{m}$ (damper: 2282510), the maximum shear deformations of the damper amount to 52, 42 and $63 \%$ of the controlled system's maximum relative displacements in the three seismic cases respectively. In ADCS2, for a DR value of 114.31/m (damper: 616355), the deformation increase of the element compared to the controlled system's relative displacements amounts to 141, 224 and $187 \%$ for the three seismic cases respectively. In ADCS3 the respective responses' increase amounts to $36.30,89.50$ and $67.59 \%$ for the three seismic cases respectively. The numerical values are included in Table 6.

\subsection{Bracings axial force}

The bracing members in all ADCS-configurations were modeled as frame objects with zero compression limits. The frames were first analyzed without pretension stress in the cables. Subsequently, for avoiding any related modification of the cables' axial forces in ADCS2 and ADCS3, these were assigned a suitable prestress through a target force. For the range of the developed stresses and strains in the bracing members, the material's mechanical behavior is 


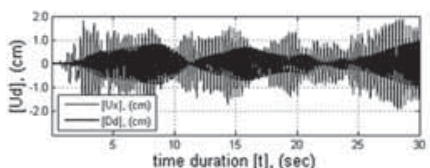

(a)

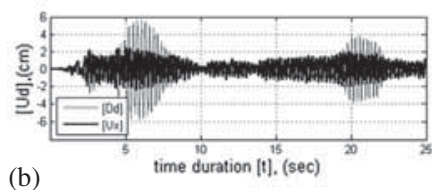

(b)
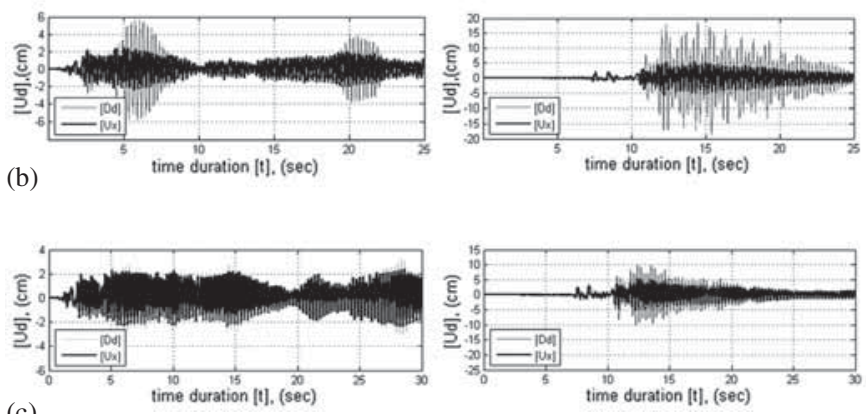

(c)

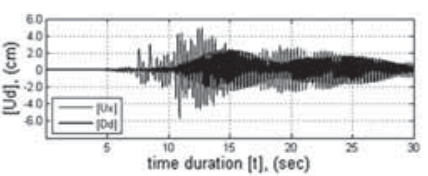

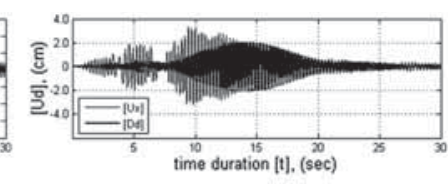
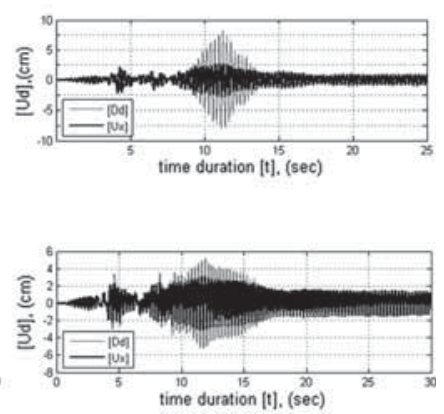

Figure 10: Optimum damper's shear deformations $\mathrm{D}_{\mathrm{d}}$ and controlled systems' relative displacements $\mathrm{U}_{\mathrm{x}}$ - time history for seismic case A, B, C (from left to right): (a) ADCS1; (b) ADCS2; (c) ADCS3.

Table 6: Optimum hysteretic dampers' shear deformations.

\begin{tabular}{lccc}
\hline & \multicolumn{3}{c}{ Max. damper's deformation [cm] } \\
\cline { 2 - 4 } System & $\mathrm{A}$ & Seismic case \\
\cline { 2 - 4 } & 0.983 & $\mathrm{~B}$ & $\mathrm{C}$ \\
\hline ADCS1 & 5.626 & 2.377 & 2.080 \\
ADCS2 & 18.65 & 8.109 \\
ADCS3 & 3.233 & 10.25 & 5.244 \\
\hline
\end{tabular}

assumed to be linear and the prestress in the cables is expected to keep them straight and taut under the seismic loads.

The static vertical and horizontal loading of the frame causes tension only to the bracings in all configurations, although under seismic loading compression has also been developed in the members. As far as the bracings rods used in ADCS1 are concerned, the resulting maximum axial tension and compression forces in the side diagonals under the seismic loadings of the analysis, amount to 164.95 and $161.01 \mathrm{kN}$ respectively in seismic case B, enabling the members' deformations to be kept within the elastic range. The implementation of cable members in ADCS1 was avoided, due to high prestress values that would be required for the members. In ADCS2 and ADCS3, the magnitude of the prestress target force is slightly higher than the maximum resulting force in the bracings when subjected under the selected seismic excitations. In seismic case B a maximum compression force of $107.35 \mathrm{kN}$ was developed in the side diagonal of ADCS2 portal bracing and a maximum compression force of $63.68 \mathrm{kN}$, in the diagonal bracing member of ADCS3. Therefore a prestress of 25 and $10 \%$ of the 
maximum allowable stress of $f_{e}=140 \mathrm{kN} / \mathrm{cm}^{2}$ was applied in each bracing respectively by following a trial and error procedure. The prestress force leads to a linear elastic resistance by the bracings under the seismic loads, with a maximum tension force of $244.94 \mathrm{kN}$ in the side diagonals of ADCS2, and $104.69 \mathrm{kN}$ in the diagonal brace of ADCS3. The respective maximum tensile stresses in the members under the seismic loads amount to 78 and $33.34 \mathrm{kN} / \mathrm{cm}^{2}$.

\section{CONCLUSIONS}

In the present study a concept of adaptable dual control systems, ADCS, based on three different bracing configurations, all formed with closed circuit and a hysteretic damper of steel plates, has been introduced. The earthquake responses of the controlled systems have been investigated based on a simplified SDOF-model and three international strong ground motions. ADCS innovative mechanism enables the elastic response of the primary structure and the dissipation of the earthquake-induced energy through plastic hysteresis of the dampers. The design configurations of the bracing-damper mechanism lead to a continuous most uniform counteraction of all structural members to resist the earthquake loading, while they practically avoid an interaction on the stiffness of the primary frame.

ADCS design considerations are linked to the optimum properties of the bracing-damper mechanism aiming at highest possible energy dissipation and control of both, base shear and relative displacements. All optimum controlled systems develop similarly high EEDI values under the seismic cases considered. Based on the mechanical properties of the primary frame and the bracings used in the numerical analyses, relatively high damper's stiffness and yield force values are required for ADCS1 optimum seismic response (factor of the damper's to the primary frame's stiffness: $\left.k_{A D C S 1}^{\prime}=k_{d} / k=0.236, P_{y}=25.09 \mathrm{kN}, \mathrm{DR}=3921 / \mathrm{m}\right)$. ADCS2 requires the comparatively lowest damper's values of stiffness and yield force for optimum seismic response $\left(k_{A D C S 2}^{\prime}=k_{d} / k=0.024, P_{y}=8.78 \mathrm{kN}, \mathrm{DR}=114.31 / \mathrm{m}\right)$. ADCS3 requires a damper's stiffness that lies between the respective values in the former systems and a yield force, slightly higher than the respective value in ADCS2 $\left(k_{A D C S 3}^{\prime}=k_{d} / k=0.129\right.$, $\left.P_{y}=11.52 \mathrm{kN}, \mathrm{DR}=466.671 / \mathrm{m}\right)$. Thus of major influence on the dampers' characteristics is the bracing configuration in each frame. The present analysis results provide a nonconservative design approach for the proposed controlled systems. Experimental investigations will support further the development of the systems.

\section{REFERENCES}

[1] Housner, G.W., Bergman, L.A., Caughey, T.K., Chassiakos, A.G., Claus, R.O., Masri, S.F., Skelton, R.E., Soong, T.T., Spencer, B.F., Jr. \& Yao, T.P., Structural control: past, present and future. Engineering Mechanics, 123(9), pp. 897-971, 1997. doi: http:// dx.doi.org/10.1061/(ASCE)0733-9399(1997)123:9(897)

[2] Martelli, A., Seismic isolation and energy dissipation: worldwide application and perspectives. Earthquake Resistant Engineering Structures VI, ed. C.A. Brebbia, WIT Press: Southampton, UK, pp. 105-116, 2007.

[3] Inoue, K. \& Kuwahara, S., Optimum strength ratio of hysteretic damper. Earthquake Engineering and Structural Dynamics, 27, pp. 577-588, 1998. doi: http://dx.doi. org/10.1002/(SICI)1096-9845(199806)27:6<577::AID-EQE743>3.0.CO;2-U

[4] Di Sarno, L. \& Elnashai, A.S., Innovative strategies for seismic retrofitting of steel and composite structures. Earthquake Engineering and Structural Dynamics, 7, pp. 115-135, 2005.

[5] Tremblay, R. \& Filiatrault, A., Seismic impact loading in inelastic tension-only concentrically braced frames: myth or reality? Earthquake Engineering and Structural 
Dynamics, 25(12), pp. 1373-1389, 1996. doi: http://dx.doi.org/10.1002/(SICI)10969845(199612)25:12<1373::AID-EQE615>3.0.CO;2-Y

[6] Filiautrault, A. \& Cherry, S., Comparative performance of friction damped systems and base isolation systems for earthquake retrofit and aseismic design. Earthquake Engineering and Structural Dynamics, 16, pp. 389-416, 1988. doi: http://dx.doi. org/10.1002/eqe.4290160308

[7] Wu, B., Zhang, J., Williams, M.S. \& Ou, J., Hysteretic behavior of improved Pall-typed frictional dampers. Engineering Structures, 27, pp. 1258-1267, 2005. doi: http://dx.doi. org/10.1016/j.engstruct.2005.03.010

[8] Mualla, I.H. \& Belev, B., Performance of steel frames with a new friction damper device under earthquake excitation. Engineering Structures, 24, pp. 365-371, 2002. doi: http:// dx.doi.org/10.1016/S0141-0296(01)00102-X

[9] Renzi, E., Perno, S., Pantanella, S. \& Ciampi, V., Design, test and analysis of a lightweight dissipative bracing system for seismic protection of structures. Earthquake Engineering and Structural Dynamics, 36(4), pp. 519-539, 2007. doi: http://dx.doi. org/10.1002/eqe.641

[10] Kurata, M., DesRoches, R. \& Leon, R.T., Cable damper bracing for partial seismic rehabilitation. Proc. of 14th World Conference on Earthquake Engineering, Beijing, China, 2008.

[11] Phocas, M.C. \& Pocanschi, A., Steel frames with bracing mechanism and hysteretic dampers. Earthquake Engineering and Structural Dynamics, 32(5), pp. 811-825, 2003. doi: http://dx.doi.org/10.1002/eqe.253

[12] Phocas, M.C. \& Sophocleous, T.L., Adaptable dual control systems for earthquake resistance. Earthquake Resistant Engineering Structures VIII, eds. C.A. Brebbia, \& M. Maugeri, WIT Press: Southampton, UK, pp. 55-66, 2011.

[13] Sophocleous, T. \& Phocas, M.C., Dual earthquake resistant frames. Earthquake Resistant Engineering Structures VII, eds. M. Phocas, C.A. Brebbia \& P. Komodromos, WIT Press: Southampton, UK, pp. 165-174, 2009. doi: http://dx.doi.org/10.2495/ ERES090151

[14] Xia, C. \& Hanson, R.D., Influence of ADAS element parameters on building seismic response. Structural Engineering, 118(7), pp. 1903-1918, 1992. doi: http://dx.doi. org/10.1061/(ASCE)0733-9445(1992)118:7(1903)

[15] Aiken, I.D., Nims, D.K., Whittaker, A.S. \& Kelly, J.M., Testing of passive energy dissipation systems. Earthquake Spectra, 9(3), pp. 335-369, 1993. doi: http://dx.doi. org/10.1193/1.1585720

[16] Tsai, K.C., Chen, H.W., Hong, C.P. \& Su, Y.F., Design of steel triangular plate energy absorbers for seismic-resistance construction. Earthquake Spectra, 9, pp. 505-528, 1993. doi: http://dx.doi.org/10.1193/1.1585727

[17] Sophocleous, T. \& Phocas, M.C., Model of analysis for earthquake resistant dual systems. Proc. of 2nd Int. Conf. on Computational Methods in Structural Dynamics and Earthquake Engineering, COMPDYN 2009, Rhodes, Greece, 2009.

[18] CSI, SAP2000NL - Structural Analysis Programs, Theoretical and Users Manual, Release No. 14.00, Computers \& Structures Inc.: Berkely, CA, USA, 2010.

[19] Nakashima, M., Saburi, K. \& Tsuji, B., Energy input and dissipation behavior of structures with hysteretic dampers. Earthquake Engineering and Structural Dynamics, 25(12), pp. 483-496, 1996. doi: http://dx.doi.org/10.1002/(SICI)10969845(199605)25:5<483::AID-EQE564>3.0.CO;2-K 